\title{
THE LABORATORY DIAGNOSIS OF VAGINAL INFEC- TIONS CAUSED BY TRICHOMONAS AND CANDIDA (MONILIA) SPECIES
}

\author{
D. A. S. EDDIE \\ Department of Obstetrics and Gynaecology, University of Leeds
}

\begin{abstract}
ALTHOUGH a provisional diagnosis of vaginal infection caused by Trichomonas vaginalis or Candida albicans may be made on clinical observation alone, in many cases the cause of vaginal discharge is not clear until laboratory investigation has been performed. Thus, a discharge that is attributed to a minor degree of cervical erosion or other visible lesion may be associated with an unsuspected infection and simple treatment of the lesion will not ensure relief of symptoms. In many cases, therefore, microscopic evidence of an infecting organism is an insurance against incomplete diagnosis.

The most common method used to aid clinical diagnosis in this way is one of the variations of a wet-smear procedure in which the motility of the trichomonas organism is detected, or candida (monilial) elements can be seen. Cultural methods can also be used, and the increased use of vaginal cytology provides a further diagnostic aid. In the present paper, a scheme for the use of these methods is proposed on the basis of the results of a retrospective study and the findings of a small prospective study.
\end{abstract}

\section{MATERIALS AND METHODS}

Women were included who had been seen at the gynaecological out-patient clinics at the Hospital for Women, Leeds, over a period of $1 \mathrm{yr}$ and in whom a laboratory diagnosis of trichomonas or candida vaginal infection was made. As laboratory records for cases found positive by direct wet-smear microscopy only were not kept, it was not possible to include all cases diagnosed by this method alone. All fungal or yeast-like infections diagnosed are referred to as due to Candida; definitive tests for Candida albicans were not performed.

Information was obtained from the consultation records, whether a clinical diagnosis of vaginal infection had been made, whether excess discharge or vaginitis had been seen, and whether there was any local lesion that had been clinically regarded as responsible for the symptoms or signs. It was also noted if a definite statement of " no vaginitis or discharge" had been made.

Vaginal cytology. The cervix was exposed with a clean vaginal speculum lubricated with warm water or sterile lubricant, and scraped with an Ayre's spatula. The spatula specimen was promptly transferred to a clean microscope slide and the smear was fixed with alcohol. The slide was stained by Papanicolaou's method, usually within $24 \mathrm{hr}$, and examined for abnormal cells. The presence of Trichomonas or Candida was recorded if seen. No prolonged or special search was made for evidence of infection. Cytological smears were not taken specifically to aid diagnosis of vaginal discharges; such

Received 17 Jan. 1968; revised MS accepted 18 Apr. 1968.

J. MED. MICROBIOL.-VOL. 1 (1968) 
a smear was taken only as a follow-up of a recent abnormal cytological smear, or as a check if no recent examination had been made for abnormal cells.

Direct microscopy. It was nearly always found that when there was an appreciable amount of vaginal discharge, some could be withdrawn on the blade of the speculum that had been used to inspect the cervix. The speculum was immediately taken to the laboratory adjacent to the clinic and a drop of the discharge was transferred to a clean microscope slide with a sterile platinum loop; a drop of aqueous methylene blue (1 in 4000) was added. A coverslip was placed over the drop and the specimen was examined microscopically for trichomonal agitation of the vaginal cells, which were lightly stained by the methylene blue. Candida infections were recognised by the presence of pseudo-hyphae or yeasts. If a speculum could not be inserted into the vagina, a sterile cotton-tipped stick was used to transfer the sample of discharge to the laboratory. In all cases microscopical examination was made within $5 \mathrm{~min}$. of collection of the specimen.

Culture. The medium used during the first part of the period under review was made up in our own laboratory by the method of Stenton (1957) and was stored and used in 5-ml screw-capped bijou bottles. The bottles of medium were stored cold, but were warmed at the beginning of a clinic. The cultures were inoculated by drawing the medium into a Pasteur pipette and releasing the fluid in the vagina around the cervix while a bivalve speculum was in situ. After a few seconds, the fluid was aspirated from the posterior fornix and returned to the bijou bottle which was then tightly capped. The medium was incubated at $37^{\circ} \mathrm{C}$ and examined at intervals for up to 5 days. In the later period of the survey, a commercially obtainable medium (Trichomonas medium no. 2, Oxoid Ltd, London) was used in exactly the same manner. No distinction is made between the two media in the results given below.

Prospective study. For a period of $1 \mathrm{mth}$ ( 9 clinic sessions) a more detailed examination was made of all vaginal discharges, to determine the possible errors in the methods being used. Cytological smears were taken as before when clinically indicated. A specimen of vaginal discharge obtained on the speculum was sent immediately to the laboratory, and was examined by direct microscopy as before. Then, regardless of the findings, the commercial medium was inoculated from the speculum-transported specimen, the medium having been pre-warmed in a $37^{\circ} \mathrm{C}$ incubator. The direct microscopy preparations were subsequently stained by Gram's method and re-examined.

\section{RESULTS}

Of 4784 cytological smears examined, 273 showed trichomonas infection and 25 showed yeast-like infection. Thus, trichomonas or candida infection was diagnosed in 298 women by examination of the cervical cytological smear. These figures do not include those cases in which the clinician had told the cytologist that this diagnosis had been made. In the same period, 1338 vaginal specimens were cultured from women with possible vaginal infection; 40 yielded Trichomonas and 60 yielded Candida. All the figures given below are taken from these two diagnosed groups of infections.

\section{Clinical assessment}

There were 181 women among those with laboratory-diagnosed infections for whom a definite clinical appraisal was noted. These were divisible into 4 groups:

(A) Trichomonas or Candida diagnosed; (B) vaginitis or excess discharge noted with no obvious causative lesion; (C) lesion seen and judged to be the 
cause of discharge (e.g., cervical erosion); (D) definite nil diagnosis, (i.e., " no vaginitis or discharge seen ").

Group $A$. Trichomonas infection was clinically diagnosed in 65 patients. Fifty-six were confirmed by microscopical techniques, but 9 of the 65 showed Candida and no Trichomonas; the incorrect diagnoses were revealed by culture in 8 cases and by direct microscopy in 1 case. All 18 cases of infection clinically ascribed to Candida were confirmed in the laboratory. Thus, the clinical diagnosis was consistent with the microscopical findings in 74 of 83 cases ( 88 per cent.).

TABLE I

Clinical diagnoses and laboratory findings in 83 cases of vaginal infection

\begin{tabular}{|c|c|c|c|c|c|c|c|}
\hline \multirow{3}{*}{$\begin{array}{l}\text { Infection } \\
\text { clinically } \\
\text { ascribed to }\end{array}$} & \multirow{3}{*}{$\begin{array}{l}\text { Number } \\
\text { of cases }\end{array}$} & \multicolumn{6}{|c|}{ Results obtained by } \\
\hline & & \multicolumn{2}{|c|}{$\begin{array}{l}\text { direct wet-film } \\
\text { microscopy }\end{array}$} & \multicolumn{2}{|c|}{$\begin{array}{l}\text { microscopy of cyto- } \\
\text { logical preparation }\end{array}$} & \multicolumn{2}{|c|}{ culture in $\mathrm{TM}^{*}$} \\
\hline & & + & - & + & - & + & - \\
\hline Trichomonas & 65 & 28 & 3 & 40 & 7 & 19 & 2 \\
\hline Candida & 18 & 5 & 0 & 5 & 9 & 13 & 1 \\
\hline
\end{tabular}

* $\mathrm{TM}=$ Trichomonas medium no. 2 (Oxoid).

Group B. In 42 patients in whom no clinical diagnosis was made, vaginal infection was suspected because there was vaginitis or excess discharge and no other visible lesion. If these cases are added to those in group A, only 74 out of 125 cases ( 59 per cent.) were correctly diagnosed. This figure may be fallaciously low, because more clinical diagnoses would probably have been made if facilities for direct microscopy of the discharge had not been immediately available.

Groups $C$ and $D$. Of the 181 patients with a definite clinical assessment, there were 56 in whom specific vaginal infection had been erroneously considered absent as evidence of trichomonas or candida infection was found on subsequent laboratory investigation.

\section{Laboratory confirmation of clinical diagnosis}

Table I shows the results of the laboratory tests in the 83 patients of group A in whom a definite clinical diagnosis of Trichomonas or Candida was made and in whom a vaginal infection caused by one or other of these organisms was proved. There were 3 patients with mixed trichomonas and candida infection and these are included in the table as correct diagnoses only, i.e., failure of the cytology smear to show Candida was not regarded as a false negative result when the associated trichomonas infection was detected. 
The results of the findings in the patients in whom infection was suspected because there was vaginitis or excess discharge without an erosion, cervical polyp or other lesion, are given in table II. This table also shows the laboratory findings for patients that were clinically believed to be normal or to have a lesion unassociated with infection, but were later found to have a specific vaginal infection.

TABLE II

The results of laboratory tests in trichomonas and candida infections

\begin{tabular}{|c|c|c|c|c|c|c|c|c|}
\hline \multirow{3}{*}{$\begin{array}{l}\text { Clinical } \\
\text { group } †\end{array}$} & \multirow{3}{*}{$\begin{array}{l}\text { Infecting } \\
\text { organism } \\
\text { detected }\end{array}$} & \multirow{3}{*}{$\begin{array}{l}\text { Number } \\
\text { of cases }\end{array}$} & \multicolumn{6}{|c|}{ Results obtained by } \\
\hline & & & \multicolumn{2}{|c|}{$\begin{array}{l}\text { direct wet-film } \\
\text { microscopy }\end{array}$} & \multicolumn{2}{|c|}{$\begin{array}{l}\text { microscopy of cyto- } \\
\text { logical preparation }\end{array}$} & \multicolumn{2}{|c|}{ culture in $\mathbf{T M}$} \\
\hline & & & + & - & + & - & + & - \\
\hline B & $\begin{array}{l}\text { Trichomonas } \\
\text { Candida }\end{array}$ & $\begin{array}{l}31 \\
11\end{array}$ & $\begin{array}{r}24 \\
2\end{array}$ & $\begin{array}{l}0 \\
1\end{array}$ & $\begin{array}{r}29 \\
1\end{array}$ & $\begin{array}{l}0 \\
7\end{array}$ & $\begin{array}{r}0 \\
10\end{array}$ & $\begin{array}{l}0 \\
0\end{array}$ \\
\hline $\mathrm{C}$ & $\begin{array}{l}\text { Trichomonas } \\
\text { Candida }\end{array}$ & $\begin{array}{r}31 \\
9\end{array}$ & $\begin{array}{l}7 \\
0\end{array}$ & $\begin{array}{l}1 \\
0\end{array}$ & $\begin{array}{r}30 \\
3\end{array}$ & $\begin{array}{l}1 \\
2\end{array}$ & $\begin{array}{l}3 \\
5\end{array}$ & $\begin{array}{l}\mathbf{0} \\
1\end{array}$ \\
\hline D & $\begin{array}{l}\text { Trichomonas } \\
\text { Candida }\end{array}$ & $\begin{array}{r}10 \\
6\end{array}$ & $\begin{array}{l}1 \\
0\end{array}$ & $\begin{array}{l}\mathbf{0} \\
\mathbf{0}\end{array}$ & $\begin{array}{l}8 \\
2\end{array}$ & $\begin{array}{l}1 \\
4\end{array}$ & $\begin{array}{l}5 \\
5\end{array}$ & $\begin{array}{l}0 \\
0\end{array}$ \\
\hline
\end{tabular}

\section{Comparability of laboratory findings}

Patients assessed in this section are those in which at least 2 of the 3 laboratory diagnostic methods considered above were used. The findings for 2 patients with mixed infections are not included in the summarised results; in one of these, Trichomonas was seen on the cytological smear and Candida was isolated on culture; the other was diagnosed as a trichomonas infection on the basis of the direct microscopy and cytological examination, but only Candida was isolated on culture. One hundred and thirty-one other patients were examined by more than one laboratory technique and the results are compared in table III.

\section{Prospective study}

Fifty-five patients were seen with significantly excessive vaginal discharges. Results of direct microscopy and culture showed that 27 had specific infections. The relative efficiencies of the diagnostic methods for the 26 patients with a single infecting organism are shown in table IV. There was one case of mixed infection, and in this instance direct microscopy and the cytology smear showed Trichomonas but Candida was detected in the Gram smear of the direct film 
and isolated on culture. A cytology smear was not taken in all cases, and on no occasion did it indicate infection that was not diagnosed by other methods.

TABLE III

Comparison of laboratory diagnostic methods for the investigation of vaginal infections caused by Trichomonas and Candida species

\begin{tabular}{|c|c|c|c|c|}
\hline \multirow{2}{*}{ Laboratory procedure } & \multicolumn{2}{|c|}{ Trichomonas infection } & \multicolumn{2}{|c|}{ Candida infection } \\
\hline & $\begin{array}{l}\text { Number of } \\
\text { cases }\end{array}$ & $\begin{array}{l}\text { Number of } \\
\text { positive results }\end{array}$ & $\begin{array}{l}\text { Number of } \\
\text { cases }\end{array}$ & $\begin{array}{l}\text { Number of } \\
\text { positive results }\end{array}$ \\
\hline $\begin{array}{l}\text { Direct microscopy of wet film } \\
\text { Cytology }\end{array}$ & 61\{ & $\begin{array}{l}56 \\
60\end{array}$ & $7 *\{$ & $\begin{array}{l}6 \\
4\end{array}$ \\
\hline $\begin{array}{l}\text { Direct microscopy of wet film } \\
\text { Culture }\end{array}$ & 4\{ & $\begin{array}{l}4 \\
4\end{array}$ & & $\begin{array}{l}3 \\
5\end{array}$ \\
\hline$\cdot \quad: \quad \cdot$ & 33\{ & $\begin{array}{l}22 \\
31\end{array}$ & 34\{ & $\begin{array}{r}5 \\
33\end{array}$ \\
\hline
\end{tabular}

* One case gave negative results in both tests.

TABLE IV

Results of investigations in a prospective study of 26 patients with vaginal discharges

\begin{tabular}{|c|c|c|c|c|c|}
\hline \multirow{2}{*}{ Infection caused by } & \multirow{2}{*}{$\begin{array}{l}\text { Number } \\
\text { of cases }\end{array}$} & \multicolumn{4}{|c|}{ Positive findings obtained by } \\
\hline & & $\begin{array}{l}\text { direct wet-film } \\
\text { microscopy }\end{array}$ & $\begin{array}{l}\text { microscopy of } \\
\text { Gram smear }\end{array}$ & culture & cytology \\
\hline Trichomonas . & 5 & 5 & 0 & 5 & 1 out of 3 \\
\hline Candida. & 21 & 8 & 14 & 19 & 2 out of 11 \\
\hline
\end{tabular}

\section{Discussion}

These results indicate that although a correct diagnosis of a vaginal infection may be made on clinical grounds in cases of gross vaginitis, many infections will not be recognised unless laboratory methods of diagnosis are also employed. In the present study, direct microscopy of fresh discharge provided a definite diagnosis in many cases especially where infection was marked; in the year's study this method gave 93 per cent. accurate results, but an infecting organism was detected in only 14 of 27 patients during the prospective study. The cytological series provided an accurate diagnosis of infection in 78.7 per cent. of the cases, but in the prospective study only 3 of 14 smears showed infecting organisms. The results obtained in the cultured series (94 per cent. correct) were comparable to those obtained with direct microscopy. 
The main differences in diagnostic accuracy depended on the infection present. In trichomonas infections, all 3 laboratory techniques gave accurate diagnostic rates of over 90 per cent. (direct microscopy, 65 of 69 positive cases; cytology, 108 of 119; culture, 32 of 34). However, in candida infections, only culture of the discharge gave comparable results, 52 of 56 cultures being positive. The infection was detected in the cytological smear in only 13 of 44 cases ( 30 per cent.), and the successful direct smear identification rate was 15 of 29 cases (52 per cent.)

It appears from the results of this survey that trichomonas infection could in most cases be diagnosed by the wet-smear technique. Hughes, Gordon and Barr (1966) found cytological smear examination to be better than cultural methods, but this was not borne out by the findings of others (Kean and Day, 1954; Burch, Rees and Reardon, 1959; Wolinska, 1959) who have shown that cultural techniques will increase the trichomonas diagnosis rate compared with that obtained by direct microscopy. As cytologists are fully occupied with malignancy screening programmes, it seems that culture of a vaginal discharge when the wet-smear preparation is negative is better than cytological examination for the purpose of diagnosing infection. This is particularly supported by the findings in candida infections; if the direct smear was negative, cytological smears did not aid diagnosis, but culture provided many positive findings. The culture medium designed for the isolation of Trichomonas vaginalis yielded monilial growth in many cases, and no special medium was included for the isolation of Candida.

Population studies in which cultural methods were used show a much higher incidence of Trichomonas or Candida in the vagina than is suggested by the reported incidence of symptoms or signs. Campbell and Parrott (1950) studied 836 women and found the incidence of yeast-like organisms in the vagina was 19.9 per cent., but almost two-thirds of those with positive cultures had no signs or symptoms of infection. Similarly, Jackson (1956) investigated 668 pregnant women and found that 33 per cent. had vaginal candidosis. Fortyeight per cent. of these women had no complaint or excess discharge, whilst 48 per cent. of those that produced negative cultures had symptoms or signs of discharge. Population surveys for trichomonas infections have also shown high incidences of infestation (Hulka and Hulka, 1967). Clark and Solomons (1959) found that 20.7 per cent. of 1016 women had Trichomonas in the vagina, and of those with no other pathogenic organisms, 25.6 per cent. had no signs or symptoms of infection.

There is probably little to be gained by routine vaginal fluid culture at a gynaecological clinic, as many patients might not require therapy even if culture were positive. It is suggested that in all women with symptoms of vaginal irritation or discharge, even if a lesion such as cervical erosion is seen, a wet-smear examination should be made; if the result of this examination is negative, the vaginal fluid should be cultured. Such a regimen should also be followed for patients who have excess discharge without symptoms. Cytological smears should be reserved for cases requiring malignant cell screening. Culture is particularly recommended as fungal infections have become commoner 
(Catterall, 1966; Seelig, 1966) and these infections are frequently not diagnosed by direct microscopy alone.

\section{SUMMARY}

A survey was made of all Trichomonas or Candida (Monilia) infections diagnosed by laboratory methods during $1 \mathrm{yr}$. Trichomonas infections were diagnosed with over 90 per cent. accuracy by wet-smear microscopy, and similar success rates were achieved by cytological examination and cultural techniques. Candida infections, however, were detected in only 52 per cent. of positive cases by direct microscopy and in only 30 per cent. by examination of cytological smears, whereas 93 per cent. of the cases were proven by culture. It is suggested that wet smears of vaginal exudate should be examined microscopically from all women with excess vaginal discharge or with symptoms of vaginal infection; if wet-smear microscopy is negative, the vaginal fluid should be cultured, even if another lesion is believed to be responsible for the discharge.

The author wishes to thank the gynaecologists of the Hospital for Women, Leeds, for allowing him to study their case records; he is indebted to the laboratory staff of the hospital for their assistance.

\section{REFERENCES}

Burch, T. A., ReEs, C. W., AND ReArdon, 1959. Amer. J. Obstet. Gynec., 77, 309. LUCY

Campbell, R. M., and Parrott, M. H. 1950. Ibid., 59, 1005.

Catterall, R. D. . . . . . . . 1966. Lancet, 2, 830.

Clark, D. H., and Solomons, E. . . 1959. Amer. J. Obstet. Gynec., 78, 1314.

Hughes, Helena E., Gordon, A. M., 1966. J. Obstet. Gynaec. Br. Commonw., 73, AND BARR, G. T. D. 821.

Hulka, Barbara S., And Hulka, J. F. . 1967. Amer. J. Obstet. Gynec., 98, 180.

JACKSON, J. L. . . . . . . . . . . 1956. Ibid., 72, 648.

KEAN, B. H., AND DAY, E. $\quad$. . . . . 1954. Ibid., 68, 1510.

SeElig, M. S. . . . . . . . . 1966. Amer. J. Med., 40, 887.

Stenton, P. . . . . . . . . . . 1957. J. Med. Lab. Technol., 14, 228.

Wolinska, Wanda H. . . . . . 1959. Amer. J. Obstet. Gynec., 77, 306. 